\title{
Evaluation of combinatorial cis-regulatory elements for stable gene expression in chicken cells
}

Hee W Seo ${ }^{1}$, Tae M Kim¹, Jin W Choi ${ }^{1}$, Beom K Han², Gwonhwa Song ${ }^{1}$, Jae Y Han ${ }^{1 *}$

\begin{abstract}
Background: Recent successes in biotechnological application of birds are based on their unique physiological traits such as unlimited manipulability onto developing embryos and simple protein constituents of the eggs. However it is not likely that target protein is produced as kinetically expected because various factors affect target gene expression. Although there have been various attempts to minimize the silencing of transgenes, a generalized study that uses multiple cis-acting elements in chicken has not been made. The aim of the present study was to analyze whether various cis-acting elements can help to sustain transgene expression in chicken fibroblasts.

Results: We investigated the optimal transcriptional regulatory elements for enhancing stable transgene expression in chicken cells. We generated eight constructs that encode enhanced green fluorescent protein (eGFP) driven by either CMV or CAG promoters (including the control), containing three types of key regulatory elements: a chicken lysozyme matrix attachment region (CMAR), 5'-DNase I-hypersensitive sites 4 (CHS4), and the woodchuck hepatitis virus posttranscriptional regulatory element (WPRE). Then we transformed immortalized chicken embryonic fibroblasts with these constructs by electroporation, and after cells were expanded under G418 selection, analyzed mRNA levels and mean fluorescence intensity (MFI) by quantitative real-time PCR and flow cytometry, respectively. We found that the copy number of each construct significantly decreased as the size of the construct increased $\left(R^{2}\right.$ $=0.701)$. A significant model effect was found in the expression level among various constructs in both mRNA and protein $(P<0.0001)$. Transcription with the CAG promoter was 1.6-fold higher than the CMV promoter $(P=0.027)$ and the level of eGFP expression activity in CMAR- or CHS4-flanked constructs increased by two- to three-fold compared to the control CMV or CAG promoter constructs. In addition, flow cytometry analysis showed that constructs having cis-acting elements decreased the level of gene silencing as well as the coefficient of variance of eGFP-expressing cells $(P<0.0001)$.

Conclusions: Our current data show that an optimal combination of cis-acting elements and promoters/enhancers for sustaining gene expression in chicken cells is suggested. These results provide important information for avian transgenesis and gene function studies in poultry.
\end{abstract}

\section{Background}

The delivery of gene constructs into animal cells is an indispensible tool for conducting various biomedical studies and producing transgenic animals. However, several aspects should be taken into consideration for successful

\footnotetext{
* Correspondence: jaehan@snu.ac.kr

'WCU Biomodulation Major, Department of Agricultural Biotechnology and Research Institute for Agriculture and Life Sciences, Seoul National University, Seoul 151-921, Korea

Full list of author information is available at the end of the article
}

transgene expression in target cells. The extent of transgene expression largely depends on multiple aspects, such as gene delivery method, cellular physicochemical properties, and the traits of the construct [1]. Although methods for gene transfer into the host cells are currently standarized in several cell types, the transfection efficiency remains unsatisfactory in many cases and efforts to devise an optimal construct that can induce constant expression have not been very promising. In addition, many obstacles, such as transgene silencing 
and variegation, have yet to be overcome to enhance transgene expression [2].

To date, various strong enhancers/promoters have been used for stable expression of transgenes in animal cells. Among these, the cytomegalovirus (CMV) immediate-early enhancer/promoter and CAG (CMV enhancer with a chicken beta-actin transcription start site and a rabbit beta-globin intron) promoters have been used in a variety of cells due to their ability to induce immediate and strong transcription [3,4]. However, the two promoters exhibit different transcriptional activities, presumably due to distinctive constituents [5-7]. Other studies have also shown transcriptional variation among different tissues or developmental stages [8-11].

Other transcription regulator elements have also been used to sustain transcription activity. Chicken 5'DNase I-hypersensitive sites 4 (cHS4), derived from the chicken beta-globin locus, contains GC-rich DNA sequences and a CTCF-dependent element linked to the nuclear matrix $[12,13]$. It enhances transgene expression in cultured cells [14] and transgenic animal cells [15], and prevents silencing of viral vectors $[16,17]$. The woodchuck hepatitis virus posttranscriptional regulatory element (WPRE) is derived from the $3^{\prime}$ untranslated region (3' UTR) of viral RNA [18] and acts as a posttranscriptional enhancer by stimulating the cytoplasmic import of mRNAs $[19,20]$. The matrix attachment region (cMAR) from the $5^{\prime}$ regulatory region of the chicken lysozyme gene contains AT-rich sequences and enhances transgene expression in various immortalized cells [21,22], transgenic animals $[23,24]$, and plants [25].
Birds serve as excellent models of disease and bioreactor production due to the ease of embryo manipulation and the availability of various transgenic technologies using primordial germ cells and testicular cells [26]. However, only a limited number of recently refined constructs carrying transcription activators have been used for inducing stable gene expression in transgenic birds. Therefore, we evaluated whether these multiple transcription regulators can help maintain stable gene expression in chicken cells, and propose an optimal construct with an optimal combination of promoter/enhancer and transcription regulatory units.

\section{Results}

Correlation between size and copy number of the delivered plasmids

Given that each vector contained different promoters and cis-acting elements, their sizes were variable (Fig. 1). Therefore, we examined the relationship between vector size and the integrated vector copy numbers. Relative vector copy numbers were generally reduced as vector size increased $\left(R^{2}=0.701\right.$; Fig. 2$)$.

\section{CMV and CAG promoter transcription activities differ in chicken embryonic fibroblasts}

To compare the strength of the CMV and CAG promoters, mRNA levels were measured by real-time PCR. MFI was analyzed by flow cytometry to study transgene expression levels induced by the CMV and CAG promoters in DF-1 cells. The difference in mRNA expression levels between the CMV and CAG promoters was not significant $(P=0.35)$, whereas the MFI of

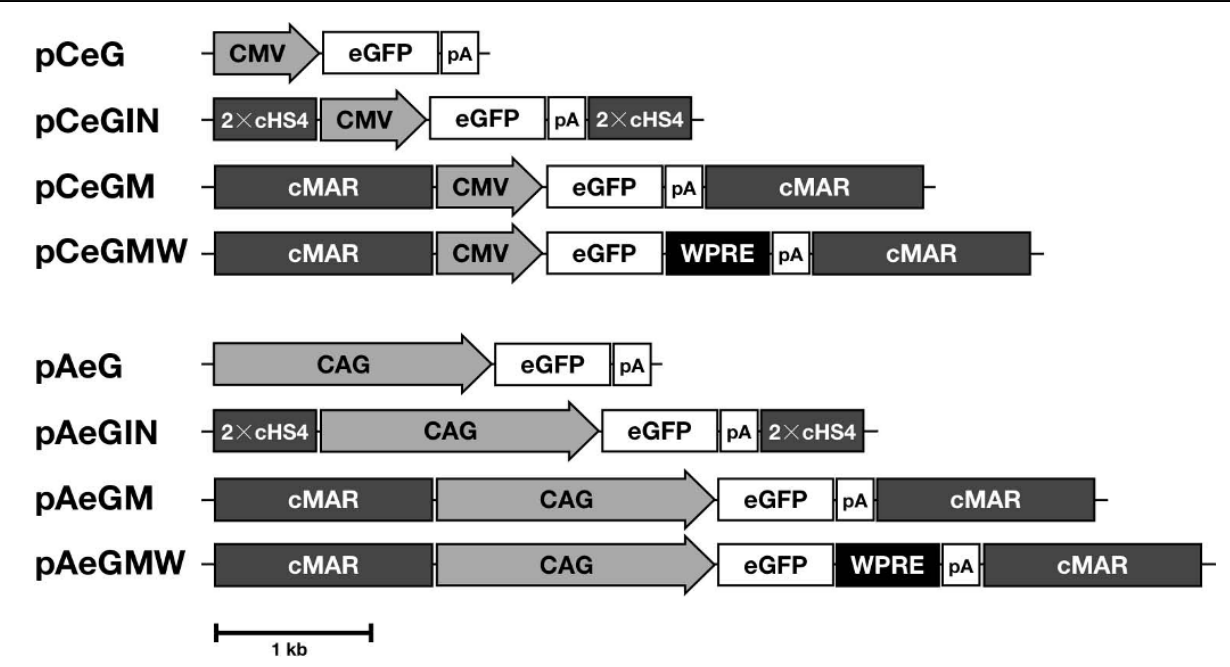

Figure 1 Construction of the vectors containing different cis-regulatory elements. CMV, human cytomegalovirus immediate-early enhancer/promoter; CAG, CMV enhancer + chicken beta-actin promoter + rabbit beta-globin intron; eGFP, enhanced green fluorescent protein; pA, bovine growth hormone polyadenylation signal; CMAR, chicken lysozyme matrix attachment region (BamHI-Pvul fragment); cHS4, the core region of chicken beta-globin insulator (250bp); WPRE, woodchuck hepatitis virus posttranscriptional regulatory element. 


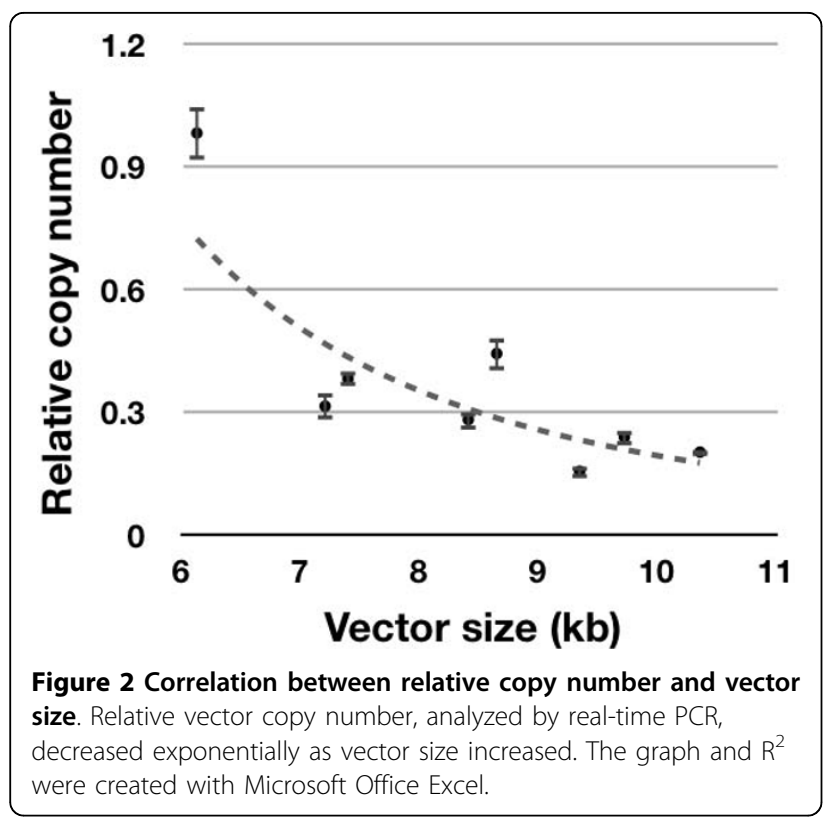

the CAG promoter (pAeG) was 1.6-fold higher than that of the CMV promoter (pCeG) $(\mathrm{P}=0.027$; Fig. 3a, b). When HS4 was juxtaposed to the $5^{\prime}$ and $3^{\prime}$ regions of the transgene cassette, the difference in mRNA levels and MFI values between the two promoters was not significant $(\mathrm{P}>0.05$; Fig. $3 \mathrm{a}, \mathrm{b})$. However, the transcript level generated by the CAG promoter was 1.5-fold higher than that generated by CMV in MARflanked plasmids (pCeGM versus pAeGM, P = 0.0439; Fig. 3a).

\section{cMAR and cHS4 enhance transgene expression}

Both cMAR and cHS4 increased eGFP expression in mRNA and protein (Fig. 3a, b). The CMV promoter led to increases of 2.9-fold and more than 3.0-fold in mRNA $(\mathrm{P}=0.0052)$ and MFI $(\mathrm{P}<0.0001)$, respectively, in $\mathrm{pCeGIN}$ compared to those of the control pCeG. Adding cMAR (pCeGM) yielded an approximately 2.6fold increase in mRNA expression level $(\mathrm{P}=0.018)$ and 3.5 -fold increase in MFI value $(\mathrm{P}<0.0001)$ relative to pCeG. The CAG promoter led to increases of 2.1 -fold $(\mathrm{P}=0.0086)$ and 1.9 -fold $(\mathrm{P}=0.0001)$, respectively, in the HS4-flanked plasmid (pAeGIN) compared to the control pAeG. Likewise, cMAR led to increases of 2.5fold $(\mathrm{P}=0.0014)$ and 2.1 -fold $(\mathrm{P}<0.0001)$, respectively, in pAeGM compared to pAeG. To investigate the effects of cHS4 and cMAR on eGFP expression at the singlecell level, flow cytometry was performed. A considerable proportion of the cells with transgene suppression were noted in control plasmids (Fig. 4a, arrows); however, adding cHS4 or cMAR clearly reduced the level of such heterogeneity. Furthermore, the coefficient of variation (CV) of eGFP-expressing cells was reduced in the vector with cHS4 and cMAR ( $<1 \times 10^{-5}$; Fig. $\left.4 \mathrm{~b}\right)$.

\section{The effect of WPRE is promoter-dependent}

pCeGMW increased eGFP expression in both mRNA (2.4-fold, $\mathrm{P}<0.0001)$ and MFI (1.7-fold, $\mathrm{P}<0.0001)$ compared to the control pCeGM (Fig. 3a, b). With the CAG promoter, pAeGMW did not induce a dramatic increase in mRNA level $(P=0.1482)$, whereas an increase was noted in the MFI compared to pAeGM

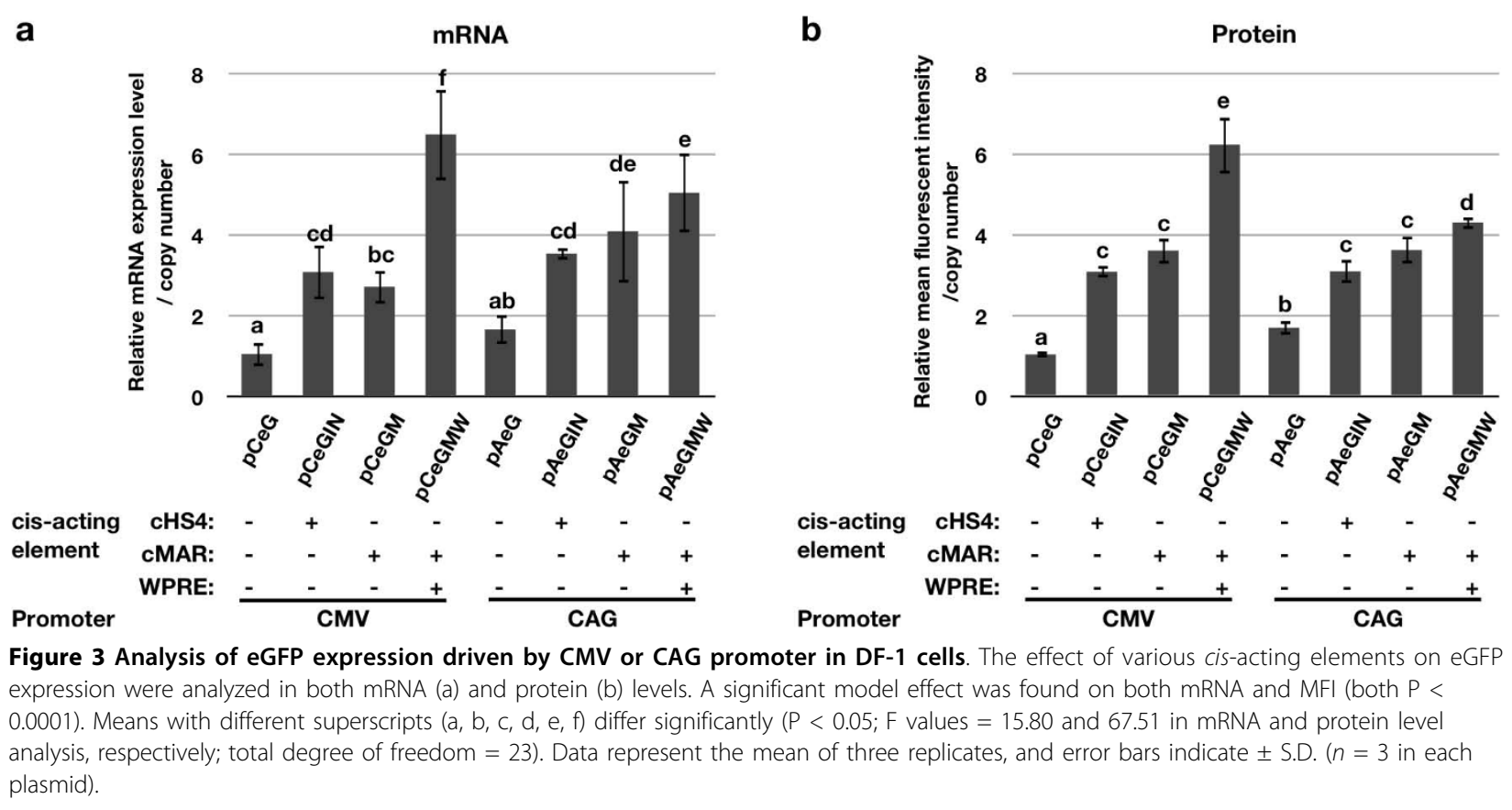




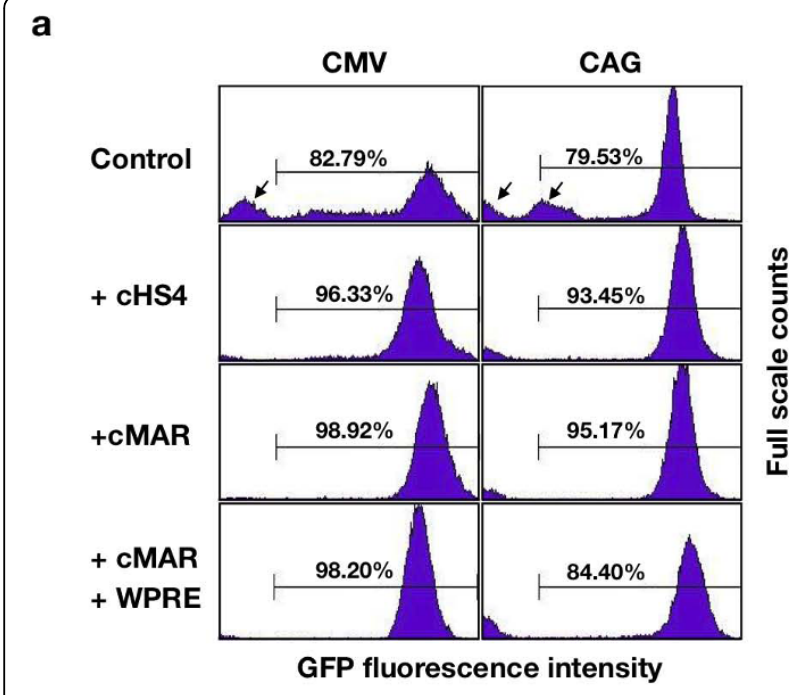

b

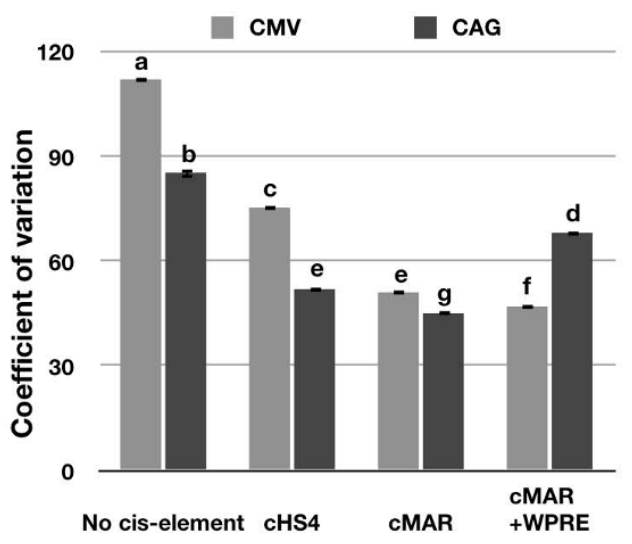

Figure 4 Flow cytometry analysis of electroporated DF-1 cells. (a) The proportion of eGFP-expressing cells are indicated. Arrows denote cells of the non-expressing population. (b) The effect of cis-acting elements on the coefficient of variation (CV) in eGFP expression driven by CMV and CAG promoters. A significant model effect was found on $C V$ among the eight constructs $(P<0.0001)$. Means with different letters $(a, b, c, d, e, f, g)$ differ significantly $(P<$ $0.05 ; \mathrm{F}$ value $=2927.53$; total degree of freedom $=23$ ). Data represent the mean of three replicates, and error bars indicate \pm S.D. $(n=3$ in each plasmid).

(1.2 folds, $\mathrm{P}=0.0238$ ). The level of transcription silencing in each construct was then analyzed by flow cytometry, which revealed an increase in the proportion of eGFP-positive cells in HS4-, MAR-, and MAR+WPREinserted constructs compared to those transfected with control plasmids ( $\mathrm{pCeG}$ and $\mathrm{pAeG}$ ). However, in pAeGMW, the eGFP-positive population decreased compared to those of pAeGM and pAeGIN. A significant model effect was found on the CV of eight constructs that were tested $(\mathrm{P}<0.0001)$. Generally, the CAG promoter constituted less heterogeneity in eGFP expression compared to CMV, except in the construct with MAR and WPRE, for which the CV of CAG (pAeGMW) was higher than that of CMV (pCeGMW, Fig. $4 b)$.

\section{Discussion}

Birds are an excellent model for studying transgenic animals and disease because of their physiological uniqueness during embryogenesis [26-29]. Various methods for producing transgenic birds have been developed over the last two decades [30-33] however, optimized gene constructs are lacking. Therefore, to develop an efficient non-viral vector system in chicken, we examined three regulatory elements for high transgene expression: (1) promoter/enhancer elements, (2) cis-acting elements for blocking the position effect, and (3) posttranscriptional elements associated with RNA processing.

We described and compared the role of the various cis-acting elements as well as the efficacy of combinatorial regulatory elements to allow for enhanced regulation of transfected genes. To identify optimal combinations of cis-acting elements for efficient transgene expression, we constructed eight non-viral vectors containing various cis-regulatory elements. Furthermore, we compared the CMV and CAG promoters to identify the most appropriate promoter for enhancing transgene expression. Considering the position effects caused by the chromosomal environment in the host cells, cMAR and cHS4 derived from chicken genomic sequences were tested. In addition, WPRE was inserted into the downstream region of the open reading frame of the eGFP gene to increase transgene expression levels via posttranscriptional regulation of transcripts.

The relative vector copy numbers decreased as vector size increased, which has also been reported in previous studies. For example, the gene-transfer capacity of plasmid DNA has been shown to be inversely related to the vector size, and furthermore, gene expression decreases as the size of DNA increases [34,35]. Given that the electroporation performed in the present study contributed to the delivery of plasmid DNA into the cytoplasm, our results may be due to a decrease in DNA diffusion mobility from the cytoplasm to the nucleus as the vector size increased [36,37].

The CAG promoter was more effective than the CMV promoter for transgene expression in DF-1 cells, possibly due to differences in the promoter constituents. The CMV promoter originated from the immediate-early gene of human CMV did not contain the intron sequence [38], whereas the CAG promoter consisted of the same CMV immediate-early enhancer with a chicken beta-actin promoter and rabbit beta-globin intron [5]. The presence of an intron in the promoter affects transgene expression in mammalian cells [5], and inserting a large CMV intron and beta-actin intron into 
plasmids with the same promoter increases luciferase activity [6]. Therefore, our results support previous studies showing the roles of the chicken beta-actin promoter and rabbit beta-globin introns in the CAG promoter in improving the efficiency of transgene expression [5].

The chicken HS4 insulator, which contains a CTCFbinding site, enters the nuclear matrix and forms nucleosome gaps by binding with CTCF [39]. The expression of the transgene cassette flanked by the HS4 insulator is not affected by other neighboring chromosomal elements such as enhancers [40]. The MAR element, which consists of AT-rich DNA, makes an independent loop or domain in the chromatin by binding to nuclear matrix proteins such as topoisomerase II, histone H1, lamins, SP120, ARBP, and SATB1. Using this mechanism, interferences with chromosomal structures surrounding the gene cassettes are blocked, thereby enhancing the binding of the transcription factor to the regulatory region [41]. In the present study, we also found that cHS4 and cMAR increased the number of transfected cells and reduced variation in eGFP expression. Therefore, our data indicate that $2 \times \mathrm{cHS} 4$ and cMAR prevent position effects that exert an inhibitory effect on transgene expression in chicken cells.

WPRE, which is associated with RNA processing, has a pivotal regulatory element for efficient transgene expression. It can enhance transgene expression related to splicing and polyadenylation, export it into the cytoplasm, and stabilize the mRNA transcript [18]. When combined with the appropriate regulatory elements, WPRE promotes the cytoplasmic export of nuclear mRNA without introns $[42,43]$. In addition, when inserted into the $3^{\prime}$ UTR of non-viral vectors, it increases transgene expression in mammalian cells [44]. Our current results showed that WPRE improves eGFP expression driven by CMV and CAG promoters in DF-1 cells. However, this effect is promoter-dependent. When WPRE was added, the increase in eGFP expression was higher in the vector combined with the CMV promoter than with CAG. These results support the idea that the effect of WPRE depends on what constitutes the promoter [45].

We have produced germline chimeric chicken [46-49] and quail $[50,51]$ using various types of germ cells to establish avian transgenesis. Among various donor cells that generate chimeras, the potential of primordial germ cells (PGCs) is limitless based on their ability to migrate towards the sex cord in the recipient embryo, and subsequent testcross analyses allows the production of donor-derived offspring. However, there are several obstacles to this process because germ cells are relatively transcriptionally quiescent and prone to switching off transgene expression [52,53]. Our results can be directly applied to genetic and cellular manipulation systems for transgenesis via an increase in transcription activity, thus preventing position effects provoked by nearby enhancers/suppressors and increasing cytoplasmic export of transcripts by stabilizing mRNA.

\section{Conclusions}

The purpose of this research was to develop a non-viral vector system with minimized transgene silencing in chicken cells. The application of cHS4 and cMAR effectively reduced the silencing of transgene expression, while WPRE enhanced the expression level. Our data constitute optimized regulatory elements that can be used to induce stable gene expression and study gene function in chicken. The present research also provides new insights to establish the bioreactor and model bird production system using avian transgenic technology.

\section{Methods \\ Vector construction}

To construct pCeG, the EcoR I-Xba I fragment of eGFP from pEGFP-1 (Clontech, Mountain View, CA) was inserted into pcDNA3 (Invitrogen, Carlsbad, CA) containing the CMV promoter (Fig. 1). To construct pAeG, the Spe I-EcoR I fragment of the CAG promoter from pCAGGS [5] was inserted into pCeG. The BP-MAR fragment [54] was derived from the PCR product of chicken genomic DNA using the primer set P1 (5'-CGC TCT AGA ACT AGT GGG ATC CAT-3') and P2 (5'ATG CCT GTT GCA GCT GTT TAC G-3'), which was then inserted into Bgl II and Dra III sites of pCeG and pAeG, thus constructing pCeGM and pAeGM, respectively. pCeGIN and pAeGIN were constructed inserting the tandem-duplicated cHS4 $(2 \times \mathrm{HS} 4)$ fragment, which was amplified from chicken genomic DNA using P3 (5'-GCA GGT TTC CTG GAA GGT-3') and P4 (5'-AGC TAA AGC TTT TTC CGT-3') primers, into $B g l$ II and Dra III sites of pCeG and pAeG, respectively [55]. To construct pCeGMW and pAeGMW, the WPRE fragment was amplified from $\mathrm{pWPI}$ by PCR using P5 (5'-GCG GCC GCG ACC TCG AGG GAA TTC CGA T-3') and P6 (5'-GCG GCC GCT TCG AAG CTT GAC GAA TTC C-3') primers. The PCR product was then inserted into a Not I site of pCeGM and pAeGM. A schematic diagram of the vectors is illustrated in Figure 1.

\section{Cell culture and transfection}

DF-1 (ATCC, Manassas, VA, Cat. No. CRL-12203) cells were cultured in Dulbecco's Modified Eagle medium (Invitrogen, Carlsbad, CA) supplemented with 10\% fetal bovine serum (FBS, Invitrogen) and $1 \times$ antibiotic-antimycotics (Invitrogen) in an incubator at $37^{\circ} \mathrm{C}$ and $5 \%$ $\mathrm{CO}_{2}$ in an air atmosphere with $60-70 \%$ relative humidity. Transfection was performed as described previously 
[56]. Briefly, a total of $1 \times 10^{6}$ of cells were suspended in serum-free OPTIMEM-I (Invitrogen) with the same molar ratio of linearized plasmid DNAs in a 0.4-cm cuvette (Bio-Rad, Hercules, CA) and electroporation was performed using Gene Pulser Xcell ${ }^{\mathrm{TM}}$ (Bio-Rad). The transfected cells were selected with $400 \mu \mathrm{g} / \mathrm{ml}$ G418 (Invitrogen) for 21 days and cultured at least 90 days before further analysis. Three cell lines in each plasmid were subjected to analysis of eGFP expression.

\section{Quantitative real-time PCR}

Total RNA was isolated from G418-selected cells using TRIZOL $^{\oplus}$ Reagent (Invitrogen). cDNA was synthesized using the SuperScript ${ }^{\odot}$ III First-Strand Synthesis kit (Invitrogen) according to the manufacturer's protocol. Genomic DNA was extracted from cells using Wizard ${ }^{\circledR}$ SV Genomic DNA purification system (Promega, Madison, WI) according to the manufacturer's instructions. The expression level of mRNA from the cells electroporated with various constructs were compared to those with pCeG and measured in triplicate using real-time PCR (ABI 7300 Real-Time PCR system, Applied Biosystems, Foster City, CA) and SYBR ${ }^{\oplus}$ Green (Sigma, St. Louis, MO). To measure and compare relative mRNA expression levels, the measured values were divided by the copy numbers of their relative vectors $[45,54]$. The primers used for quantitative PCR were eGFP-forward (5'-TCA AGG ACG ACG GCA ACT ACA A-3'), eGFPreverse (5'-GAT GGG GGT GTT CTG CTG GT-3'), GAPDH-forward (5'-TCA CAG CCA CAC AGA AGA CGG-3'), and GAPDH-reverse (5'-CAG ACG GCA GGT CAG GTC AA-3'). Relative quantification of mRNA expression was calculated using the $2^{-\Delta \Delta C t}$ method [57].

\section{Flow cytometry}

Flow cytometry was performed using a FACS Calibur ${ }^{\text {т }}$ flow cytometer (BD Biosciences, San Jose, CA) and CellQuest software (BD Biosciences) equipped with a standard fluorescence filter set. Trypsinized cells were resuspended in phosphate buffered saline (PBS, Invitrogen) supplemented with 3\% FBS. The mean fluorescence intensity (MFI) and coefficient of variation (CV) were also obtained by flow cytometry.

\section{Statistical analysis}

Data were subjected to analysis of variance (ANOVA) according to the general linear model (PROC-GLM) of the SAS program (SAS Institute, Cary, NC). If the main effect was significant, treatment effects were compared by the least squares method. P-values of less than 0.05 were considered statistically significant.

\section{Acknowledgements}

We thank D. Trono (École Polytechnique Fédérale de Lausanne, Lausanne, Switzerland) for providing the pWPI. This research was supported by a grant from the BioGreen 21 Program of Rural Development Administration. This was also supported by WCU (World Class University) program (R31-10056) through the National Research Foundation of Korea funded by the Ministry of Education, Science and Technology.

\section{Author details}

${ }^{1}$ WCU Biomodulation Major, Department of Agricultural Biotechnology and Research Institute for Agriculture and Life Sciences, Seoul National University, Seoul 151-921, Korea. ${ }^{2}$ Avicore Biotechnology Institute, Optifarm Solution Inc., Hanlim Human Tower \#707, Gyeonggi-do, 435-050, Korea.

\section{Authors' contributions}

$\mathrm{JYH}$, as a Corresponding author, conceived of the study, and participated in its design, collected data, interpreted the research results and edited the manuscript. JYH supervised HWS, prepared and submitted the manuscript. HWS designed and constructed plasmids, carried out the chicken cell culture and transfection, performed quantitative real-time PCR and flow cytomestry, and conducted the statistical analysis of data. HWS drafted and edited the manuscript. TMK participated with the statistical analysis and interpretation of data, provided the advice on plasmid design and transfection of chicken cells, and edited the manuscript. JWC provided technical assistance with quantitative real-time PCR, participated with manuscript preparation. BKH provided the advice on background studies, data interpretation and manuscript editing. GS provided the advice on interpretation of data, corrected and edited the manuscript. The final manuscript was read and approved by all authors.

Received: 3 March 2010 Accepted: 19 September 2010 Published: 19 September 2010

\section{References}

1. Ausubel FM: Short protocols in molecular biology: a compendium of methods from Current protocols in molecular biology. New York: Wiley, 4 1999.

2. Ellis J: Silencing and variegation of gammaretrovirus and lentivirus vectors. Hum Gene Ther 2005, 16(11):1241-1246.

3. Ward CM, Stern PL: The human cytomegalovirus immediate-early promoter is transcriptionally active in undifferentiated mouse embryonic stem cells. Stem Cells 2002, 20(5):472-475.

4. Nitta Y, Kawamoto S, Halbert C, Iwata A, Miller AD, Miyazaki J, Allen MD: A CMV-actin-globin hybrid promoter improves adeno-associated viral vector gene expression in the arterial wall in vivo. J Gene Med 2005, 7(10):1348-1355.

5. Niwa H, Yamamura K, Miyazaki J: Efficient selection for high-expression transfectants with a novel eukaryotic vector. Gene 1991, 108(2):193-199.

6. Xu ZL, Mizuguchi H, Ishii-Watabe A, Uchida E, Mayumi T, Hayakawa T: Optimization of transcriptional regulatory elements for constructing plasmid vectors. Gene 2001, 272(1-2):149-156.

7. Wang S, Hu C, Zhu J: Transcriptional silencing of a novel hTERT reporter locus during in vitro differentiation of mouse embryonic stem cells. $\mathrm{Mol}$ Biol Cell 2007, 18(2):669-677.

8. Ramezani A, Hawley TS, Hawley RG: Lentiviral vectors for enhanced gene expression in human hematopoietic cells. Mol Ther 2000, 2(5):458-469.

9. Hong S, Hwang DY, Yoon S, Isacson O, Ramezani A, Hawley RG, Kim KS: Functional analysis of various promoters in lentiviral vectors at different stages of in vitro differentiation of mouse embryonic stem cells. $\mathrm{Mol}$ Ther 2007, 15(9):1630-1639.

10. Liu Y, Okada T, Nomoto T, Ke X, Kume A, Ozawa K, Xiao S: Promoter effects of adeno-associated viral vector for transgene expression in the cochlea in vivo. Exp Mol Med 2007, 39(2):170-175.

11. Xia $X$, Zhang $Y$, Zieth $C R$, Zhang SC: Transgenes delivered by lentiviral vector are suppressed in human embryonic stem cells in a promoterdependent manner. Stem Cells Dev 2007, 16(1):167-176.

12. Walters MC, Fiering S, Bouhassira EE, Scalzo D, Goeke S, Magis W, Garrick D, Whitelaw E, Martin DI: The chicken beta-globin 5'HS4 boundary element blocks enhancer-mediated suppression of silencing. Mol Cell Biol 1999, 19(5):3714-3726. 
13. Burgess-Beusse B, Farrell C, Gaszner M, Litt M, Mutskov V, Recillas-Targa F, Simpson $M$, West A, Felsenfeld $G$ : The insulation of genes from external enhancers and silencing chromatin. Proc Natl Acad Sci USA 2002, 99(Suppl 4):16433-16437.

14. Villemure JF, Savard N, Belmaaza A: Promoter suppression in cultured mammalian cells can be blocked by the chicken beta-globin chromatin insulator 5'HS4 and matrix/scaffold attachment regions. J Mol Biol 2001, 312(5):963-974.

15. Rival-Gervier S, Pantano T, Viglietta C, Maeder C, Prince S, Attal J, Jolivet G, Houdebine LM: The insulator effect of the $5^{\prime} \mathrm{HS} 4$ region from the betaglobin chicken locus on the rabbit WAP gene promoter activity in transgenic mice. Transgenic Res 2003, 12(6):723-730.

16. Jakobsson J, Rosenqvist N, Thompson L, Barraud P, Lundberg C: Dynamics of transgene expression in a neural stem cell line transduced with lentiviral vectors incorporating the cHS4 insulator. Exp Cell Res 2004, 298(2):611-623.

17. Aker M, Tubb J, Groth AC, Bukovsky AA, Bell AC, Felsenfeld G, Kiem HP, Stamatoyannopoulos G, Emery DW: Extended core sequences from the cHS4 insulator are necessary for protecting retroviral vectors from silencing position effects. Hum Gene Ther 2007, 18(4):333-343.

18. Donello JE, Loeb JE, Hope TJ: Woodchuck hepatitis virus contains a tripartite posttranscriptional regulatory element. J Virol 1998, 72(6):5085-5092

19. Loeb JE, Cordier WS, Harris ME, Weitzman MD, Hope TJ: Enhanced expression of transgenes from adeno-associated virus vectors with the woodchuck hepatitis virus posttranscriptional regulatory element: implications for gene therapy. Hum Gene Ther 1999, 10(14):2295-2305.

20. Mastroyiannopoulos NP, Feldman ML, Uney JB, Mahadevan MS, Phylactou LA: Woodchuck post-transcriptional element induces nuclear export of myotonic dystrophy $3^{\prime}$ untranslated region transcripts. EMBO Rep 2005, 6(5):458-463.

21. Phi-Van L, von Kries JP, Ostertag W, Stratling WH: The chicken lysozyme 5' matrix attachment region increases transcription from a heterologous promoter in heterologous cells and dampens position effects on the expression of transfected genes. Mol Cell Biol 1990, 10(5):2302-2307.

22. Girod PA, Zahn-Zabal M, Mermod N: Use of the chicken lysozyme 5' matrix attachment region to generate high producer $\mathrm{CHO}$ cell lines. Biotechnol Bioeng 2005, 91(1):1-11.

23. McKnight RA, Shamay A, Sankaran L, Wall RJ, Hennighausen L: Matrixattachment regions can impart position-independent regulation of a tissue-specific gene in transgenic mice. Proc Natl Acad Sci USA 1992, 89(15):6943-6947.

24. Castilla J, Pintado B, Sola I, Sanchez-Morgado JM, Enjuanes L: Engineering passive immunity in transgenic mice secreting virus-neutralizing antibodies in milk. Nat Biotechnol 1998, 16(4):349-354.

25. Oh SJ, Jeong JS, Kim EH, Yi NR, Yi SI, Jang IC, Kim YS, Suh SC, Nahm BH, Kim JK: Matrix attachment region from the chicken lysozyme locus reduces variability in transgene expression and confers copy numberdependence in transgenic rice plants. Plant Cell Rep 2005, 24(3):145-154.

26. Han JY: Germ cells and transgenesis in chickens. Comp Immunol Microbiol Infect Dis 2009, 32(2):61-80.

27. Ivarie R: Competitive bioreactor hens on the horizon. Trends Biotechnol 2006, 24(3):99-101.

28. Smith CA, Roeszler KN, Ohnesorg T, Cummins DM, Farlie PG, Doran TJ, Sinclair AH: The avian Z-linked gene DMRT1 is required for male sex determination in the chicken. Nature 2009, 461(7261):267-271.

29. Zhao D, McBride D, Nandi S, McQueen HA, McGrew MJ, Hocking PM, Lewis PD, Sang HM, Clinton M: Somatic sex identity is cell autonomous in the chicken. Nature 2010, 464(7286):237-U115.

30. Chapman SC, Lawson A, Macarthur WC, Wiese RJ, Loechel RH, BurgosTrinidad M, Wakefield JK, Ramabhadran R, Mauch TJ, Schoenwolf GC: Ubiquitous GFP expression in transgenic chickens using a lentiviral vector. Development 2005, 132(5):935-940.

31. Koo BC, Kwon MS, Choi BR, Kim JH, Cho SK, Sohn SH, Cho EJ, Lee HT, Chang W, Jeon I, Park JK, Park JB, Kim T: Production of germline transgenic chickens expressing enhanced green fluorescent protein using a MoMLV-based retrovirus vector. FASEB J 2006, 20(13):2251-2260.

32. van de Lavoir MC, Diamond JH, Leighton PA, Mather-Love C, Heyer BS, Bradshaw R, Kerchner A, Hooi LT, Gessaro TM, Swanberg SE, Delany ME, Etches RJ: Germline transmission of genetically modified primordial germ cells. Nature 2006, 441(7094):766-769.
33. Shin SS, Kim TM, Kim SY, Kim TW, Seo HW, Lee SK, Kwon SC, Lee GS, Kim H, Lim JM, Han JY: Generation of transgenic quail through germ cellmediated germline transmission. FASEB J 2008, 22(7):2435-2444.

34. Kreiss $P$, Cameron B, Rangara R, Mailhe $P$, Aguerre-Charriol $O$, Airiau M, Scherman D, Crouzet J, Pitard B: Plasmid DNA size does not affect the physicochemical properties of lipoplexes but modulates gene transfer efficiency. Nucleic Acids Res 1999, 27(19):3792-3798.

35. Yin W, Xiang P, Li Q: Investigations of the effect of DNA size in transient transfection assay using dual luciferase system. Anal Biochem 2005, 346(2):289-294.

36. Lukacs GL, Haggie P, Seksek O, Lechardeur D, Freedman N, Verkman AS: Size-dependent DNA mobility in cytoplasm and nucleus. J Biol Chem 2000, 275(3):1625-1629.

37. Lechardeur D, Verkman AS, Lukacs GL: Intracellular routing of plasmid DNA during non-viral gene transfer. Adv Drug Deliv Rev 2005, 57(5):755-767.

38. Hennighausen L, Fleckenstein B: Nuclear factor 1 interacts with five DNA elements in the promoter region of the human cytomegalovirus major immediate early gene. EMBO J 1986, 5(6):1367-1371

39. Yusufzai TM, Felsenfeld G: The $5^{\prime}$-HS4 chicken beta-globin insulator is a CTCF-dependent nuclear matrix-associated element. Proc Natl Acad Sci USA 2004, 101(23):8620-8624.

40. Zhao H, Kim A, Song SH, Dean A: Enhancer blocking by chicken betaglobin $5^{\prime}$-HS4: role of enhancer strength and insulator nucleosome depletion. J Biol Chem 2006, 281(41):30573-30580.

41. Boulikas T: Chromatin domains and prediction of MAR sequences. Int Rev Cytol 1995, 162A: 279-388.

42. Zufferey R, Donello JE, Trono D, Hope TJ: Woodchuck hepatitis virus posttranscriptional regulatory element enhances expression of transgenes delivered by retroviral vectors. J Virol 1999, 73(4):2886-2892.

43. Gruh I, Wunderlich S, Winkler M, Schwanke K, Heinke J, Blomer U, Ruhparwar A, Rohde B, Li RK, Haverich A, Martin U: Human CMV immediate-early enhancer: a useful tool to enhance cell-type-specific expression from lentiviral vectors. J Gene Med 2008, 10(1):21-32.

44. Johansen J, Tornoe J, Moller A, Johansen TE: Increased in vitro and in vivo transgene expression levels mediated through cis-acting elements. $J$ Gene Med 2003, 5(12):1080-1089.

45. Klein R, Ruttkowski B, Knapp E, Salmons B, Gunzburg WH, Hohenadl C: WPRE-mediated enhancement of gene expression is promoter and cell line specific. Gene 2006, 372:153-161.

46. Chang IK, Jeong DK, Hong YH, Park TS, Moon YK, Ohno T, Han JY: Production of germline chimeric chickens by transfer of cultured primordial germ cells. Cell Biol Int 1997, 21(8):495-499.

47. Park TS, Jeong DK, Kim JN, Song GH, Hong YH, Lim JM, Han JY: Improved germline transmission in chicken chimeras produced by transplantation of gonadal primordial germ cells into recipient embryos. Biol Reprod 2003, 68(5):1657-1662.

48. Park TS, Hong YH, Kwon SC, Lim JM, Han JY: Birth of germline chimeras by transfer of chicken embryonic germ (EG) cells into recipient embryos. Mol Reprod Dev 2003, 65(4):389-395.

49. Lee YM, Jung JG, Kim JN, Park TS, Kim TM, Shin SS, Kang DK, Lim JM, Han JY: A testis-mediated germline chimera production based on transfer of chicken testicular cells directly into heterologous testes. Biol Reprod 2006, 75(3):380-386.

50. Kim MA, Park TS, Kim JN, Park HJ, Lee YM, Ono T, Lim JM, Han JY: Production of quail (Coturnix japonica) germline chimeras by transfer of gonadal primordial germ cells into recipient embryos. Theriogenology 2005, 63(3):774-782.

51. Park TS, Kim MA, Lim JM, Han JY: Production of quail (Coturnix japonica) germline chimeras derived from in vitro-cultured gonadal primordial germ cells. Mol Reprod Dev 2008, 75(2):274-281.

52. Leatherman $\mathrm{JL}$, Jongens TA: Transcriptional silencing and translational control: key features of early germline development. Bioessays 2003, 25(4):326-335.

53. Seydoux G, Braun RE: Pathway to totipotency: lessons from germ cells. Cell 2006, 127(5):891-904.

54. Phi-Van L, Stratling WH: Dissection of the ability of the chicken lysozyme gene $5^{\prime}$ matrix attachment region to stimulate transgene expression and to dampen position effects. Biochemistry 1996, 35(33):10735-10742.

55. Recillas-Targa F, Pikaart MJ, Burgess-Beusse B, Bell AC, Litt MD, West AG, Gaszner M, Felsenfeld G: Position-effect protection and enhancer 
blocking by the chicken beta-globin insulator are separable activities. Proc Natl Acad Sci USA 2002, 99(10):6883-6888.

56. Hong YH, Moon YK, Jeong DK, Han JY: Improved transfection efficiency of chicken gonadal primordial germ cells for the production of transgenic poultry. Transgenic Res 1998, 7(4):247-252.

57. Livak KJ, Schmittgen TD: Analysis of relative gene expression data using real-time quantitative PCR and the 2(T)(-Delta Delta C) method. Methods 2001, 25(4):402-408.

doi:10.1186/1472-6750-10-69

Cite this article as: Seo et al:: Evaluation of combinatorial cis-regulatory elements for stable gene expression in chicken cells. BMC Biotechnology 2010 10:69.

Submit your next manuscript to BioMed Central and take full advantage of:

- Convenient online submission

- Thorough peer review

- No space constraints or color figure charges

- Immediate publication on acceptance

- Inclusion in PubMed, CAS, Scopus and Google Scholar

- Research which is freely available for redistribution

Submit your manuscript at www.biomedcentral.com/submit 